\title{
Effects of Sc and Y Substitution on the Structure and Thermoelectric Properties of $\mathrm{Yb}_{14} \mathrm{MnSb}_{11}$
}

Jason H. Grebenkemper, ${ }^{1}$ Sebastian Klemenz, ${ }^{2}$ Barbara Albert, ${ }^{2}$ Sabah K. Bux ${ }^{3}$ and Susan M. Kauzlarich ${ }^{1 *}$

${ }^{1}$ Department of Chemistry, One Shields Ave, University of California, Davis, CA 95616, USA

${ }^{2}$ Technische Universität Darmstadt, Eduard-Zintl-Institute of Inorganic and Physical Chemistry, AlarichWeiss-Straße 12, D-64287 Darmstadt, Germany

${ }^{3}$ Thermal Energy Conversion Technologies Group, Jet Propulsion Laboratory, California Institute of Technology, 4800 Oak Grove Drive, MS 277-207, Pasadena, CA 91109, USA

\section{Abstract}

$\mathrm{Yb}_{14} \mathrm{MnSb}_{11}$ is the most efficient bulk p-type thermoelectric material for high temperature applications. Materials with $\mathrm{Y}$ and $\mathrm{Sc}$ substitutions in $\mathrm{Yb}_{14} \mathrm{MnSb}_{11}$ were made both in $\mathrm{Sn}$-flux and by ball milling. These small 3+ rare earth (RE) cations were introduced with the goal of providing chemical pressure on the structure. The $3+\mathrm{RE}$ is smaller than $\mathrm{Yb}^{2+}$ and also donates one additional electron to this p-type semiconductor. In $\mathrm{Yb}_{14-\mathrm{x}} \mathrm{RE}_{\mathrm{x}} \mathrm{MnSb}_{11}(\mathrm{RE}=\mathrm{Sc}, \mathrm{Y})$ the maximum $\mathrm{x}$ was about 0.5 . X-ray diffraction experiments on the single crystals obtained from Sn-flux showed that Sc preferentially substitutes for $\mathrm{Yb}(1)$ and $\mathrm{Yb}(3)$, and decreases the size of the unit cell by about $0.3 \%$. $Y$ substitutes on all $\mathrm{Yb}$ sites and increases the size of the unit cell by about $0.2 \%$. Samples with $\mathrm{Yb}_{14-\mathrm{x}} \mathrm{RE}_{\mathrm{x}} \mathrm{MnSb}_{11}(\mathrm{x} \sim 0.3)$ were prepared via powder metallurgy and spark plasma sintering for transport and thermal conductivity measurements. Electron microprobe of the Sc-substituted sample showed small regions $(\leq 1 \mu \mathrm{m})$ containing greater amounts of Sc, and X-ray powder diffraction of the ball milled Sc sample could be fitted as phase pure $\mathrm{Yb}_{14-\mathrm{x}} \mathrm{Sc}_{x} \mathrm{MnSb}_{11}$. $\mathrm{Y}$-substituted samples showed larger regions of excess $\mathrm{Y}$ in electron microprobe, and small amounts of $\mathrm{Yb}_{4} \mathrm{Sb}_{3}$ in powder $\mathrm{X}$-ray diffraction. The Sc sample has slightly reduced carrier concentration over optimized $\mathrm{Yb}_{14} \mathrm{MnSb}_{11}$, while the $\mathrm{Y}$ samples have even lower carrier concentrations. These carrier concentrations lead to comparable resistivity to $\mathrm{Yb}_{14} \mathrm{MnSb}_{11}$ in the Scsubstituted material, and higher resistivities in the Y-substituted material. All materials had similar Seebeck coefficients that slightly exceed $\mathrm{Yb}_{14} \mathrm{MnSb}_{11}$ at high temperatures, with the Sc-substituted sample having the highest despite having a higher carrier concentration. Sc-substituted samples also had a slightly higher thermal conductivity over the $Y$-substituted samples, which had comparable thermal conductivity to $\mathrm{Yb}_{14} \mathrm{MnSb}_{11}$. The $z T$ values of the $\mathrm{Sc}$ and $\mathrm{Y}$ substituted samples are similar $\left(z \mathrm{~T}_{1000 \mathrm{~K}} \sim 0.8\right)$, however below that of $\mathrm{Yb}_{14} \mathrm{MnSb}_{11}$ due to the compensation of Seebeck and resistivity.

\section{Graphical Abstract}
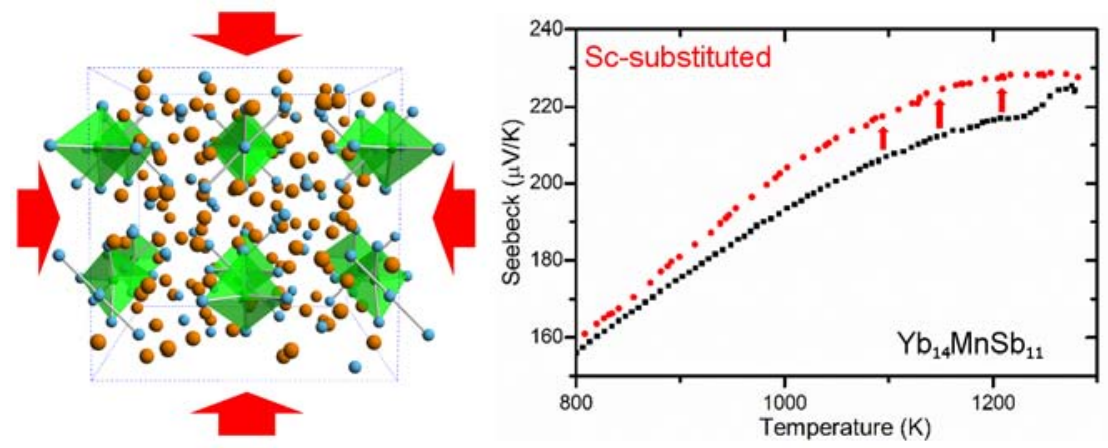


\section{Keywords}

Zintl; thermoelectric material; chemical pressure; rare earth compounds

\section{Introduction}

$\mathrm{Yb}_{14} \mathrm{MnSb}_{11}$ has been subjected to many studies due to its impressive high temperature thermoelectric properties and unique low temperature magnetism [1-3]. With a $z T \sim 1.2$ at $1200 \mathrm{~K}$, $\mathrm{Yb}_{14} \mathrm{MnSb}_{11}$ is currently the best bulk p-type material for high temperature applications [2]. The dimensionless figure of merit $z T=T\left(\frac{\alpha^{2}}{\kappa \rho}\right)$, where $T$ is the absolute temperature, $\alpha$ is the Seebeck coefficient, $\kappa$ thermal conductivity, and $\rho$ electrical resistivity, is required to be higher than 1 for efficient thermal to electrical energy conversion. $\mathrm{Yb}_{14} \mathrm{MnSb}_{11}$ is isostructural with the Zintl phase $\mathrm{Ca}_{14} \mathrm{AlSb}_{11}$ [4]. The structure consists of $14 \mathrm{Yb}^{2+}$ cations, a $\mathrm{MnSb}_{4}{ }^{9-}$ tetrahedron, a linear $\mathrm{Sb}_{3}{ }^{7-}$ chain, and 4 $\mathrm{Sb}^{3-}$ anions [3]. With three different elements to make substitutions for, this is a versatile structure whose thermoelectric properties can be further improved by tuning properties such as the carrier concentration. Studies have explored many small elemental substitutions, including Ca, La, Lu, Tm, Pr, and Sm for Yb, [5-9] Zn, Mg, and Al for Mn, [10-12] and Te for Sb [13]. By substituting a three-valent rare earth cation such as La, the carrier concentration can be reduced, increasing the resistivity and Seebeck coefficient, ultimately leading to an enhancement of the $z T$ value.

In addition to the effects of changing the cation charge, another possible method of improving thermoelectric properties involves altering the size of the unit cell [14]. Akrap et al. found that increasing pressure on $\mathrm{Yb}_{14} \mathrm{MnSb}_{11}$ resulted in an increase of the resistivity and Seebeck coefficient and attributed this effect to an increase in effective mass and narrowing of the conduction band [15]. If the increase in Seebeck coefficient is large enough to counteract the increase in resistivity, this may be a viable method for increasing thermoelectric efficiency.

Substitution of a smaller cation for a larger cation is one possible method for increasing chemical pressure by decreasing bond lengths and the size of the unit cell. This study will examine the effects of small substitutions of $\mathrm{Sc}^{3+}$ and $\mathrm{Y}^{3+}$ for $\mathrm{Yb}^{2+}$. Both cations are not only smaller than $\mathrm{Yb}^{2+}$, but also should decrease the carrier concentration by donation of an additional electron into this p-type material. Sc and $Y$ substitution for $\mathrm{Yb}$ in single crystals has been reported, leading to reduced magnetic ordering temperatures of $37(1)$ and 38(1), respectively [16]. However, no thermoelectric properties have been reported. The crystal structure and thermoelectric properties of the two substituted materials will be compared to understand the effects of chemical pressure on the material.

\section{Methods}

Synthesis. Single crystals were synthesized using a Sn-flux [17]. The elements, Yb (Stanford Material Corp, 99.99\%, dendritic), Sc and Y (Ames Lab, distilled), Sb (Alfa Aesar, 99.9999\%, shot 1-3 mm) and Sn (Alfa Aesar, 99.8\%, shot 8-20 mm), were used as provided. Mn (Alfa Aesar, 99.95\%) chips were cleaned with $5 \% \mathrm{HNO}_{3}$ in methanol prior to use. The elements were loaded into an alumina crucible in the ratio $(14-p) Y b: p R E: 6 \mathrm{Mn}: 11 \mathrm{Sb}: 86 \mathrm{Sn}(\mathrm{p}=0.2,0.4,0.6,0.8 ; \mathrm{RE}=\mathrm{Sc}, \mathrm{Y})$, sealed in a fused silica tube under vacuum and heated to $1273 \mathrm{~K}$ following the procedure established by Fisher et al [17]. After dwelling at $1273 \mathrm{~K}$ for 6 hours, the reaction mixtures were cooled at a rate of $3 \mathrm{C} / \mathrm{hr}$ to $973 \mathrm{~K}$ and the reaction vessel was removed from the furnace, inverted and centrifuged. Some of the flux reactions were heated to $1373 \mathrm{~K}$. 
Powdered samples of $\mathrm{Yb}_{14-x} \mathrm{RE}_{x} \mathrm{MnSb}_{11}(\mathrm{RE}=\mathrm{Sc}, \mathrm{Y} ; x=0.4$ ) for thermoelectric property measurements were synthesized using a variation of the previously published $\mathrm{Yb}_{14} \mathrm{MnSb}_{11}$ synthesis route [2]. Dendritic $\mathrm{Yb}$ was filed using a hardened steel rasp and $\mathrm{MnSb}$ was prepared by melting the elements together in a $1: 1$ ratio in a BN crucible sealed in a fused silica tube under vacuum at $850^{\circ} \mathrm{C}$ for 48 hours. $13.6 \mathrm{Yb}$ filings : $0.4 \mathrm{RE}$ (RE $=\mathrm{Sc}$ or $\mathrm{Y}$ pieces) $: 1 \mathrm{MnSb}$ powder were mixed in a ball mill for 5 minutes, then $10 \mathrm{Sb}$ shot was added and homogenized in a ball mill for $3 \times 30$ minutes, with scraping the walls of the container between each milling. The powder was then sealed in a $\mathrm{Nb}$ tube under Ar and annealed for two days at $1373 \mathrm{~K}$, followed by a 30 minute treatment in the ball mill, and another annealing in a $\mathrm{Nb}$ tube for two days at $1373 \mathrm{~K}$. Each preparation contained 5 grams of material, was protected from the atmosphere during milling by sealing in polyethylene bags, and was milled using a SPEX $8000 \mathrm{M}$ mixer/mill with a $5 \mathrm{~mL}$ stainless steel vial with two $7.9 \mathrm{~mm}$ tungsten carbide balls and endplates.

Spark Plasma Sintering (SPS). Powdered samples were consolidated into dense (>95\%) pellets using a Dr. Sinter-Lab SPS-211LX. The samples were sieved and loaded into graphite dies with an inner diameter of $12.7 \mathrm{~mm}$, an outer diameter of $30 \mathrm{~mm}$, and a height of $30 \mathrm{~mm}$, and a hole on the outer diameter for temperature measurement during SPS. The material was compacted with a force of $2 \mathrm{kN}$ under vacuum, heated to $973 \mathrm{~K}$ over 4 minutes, to $1023 \mathrm{~K}$ over 1 minute, the full force of $6 \mathrm{kN}$ was applied, and the temperature was held for $10 \mathrm{~min}$. The discs were sliced into two halves of approximately $1.5 \mathrm{~mm}$ thickness and polished for thermoelectric property measurements. The Sc0.4 pellet has the highest density of $8.26 \mathrm{~g} / \mathrm{cm}^{3}$, while the $\mathrm{Yb}_{14} \mathrm{MnSb}_{11}$ pellet has a density of $8.15 \mathrm{~g} / \mathrm{cm}^{3}$ and the Y0.4-A and Y0.4-B pellets have densities of $8.09 \mathrm{~g} / \mathrm{cm}^{3}$ and $7.90 \mathrm{~g} / \mathrm{cm}^{3}$, respectively

Electron Microprobe. Single crystals and pieces of the pressed pellets were analyzed with a Cameca SX100 Electron Probe Microanalyzer with a wavelength-dispersive X-ray spectrometer. The samples were placed in epoxy and polished to provide flat surfaces for analysis. SEM and elemental mapping were employed to ensure uniform elemental distributions. At least 10 different points with a spot size of $1 \mu \mathrm{m}$ were analyzed for each sample using an $\mathrm{Yb}_{14} \mathrm{MnSb}_{11}$ crystal, yttrium aluminum garnet, and Sc metal as standards.

Single Crystal X-ray Diffraction. Single crystal diffraction was measured at a Bruker APEX II diffractometer with a CCD detector. The measurement were performed with Mo radiation $\left(\lambda_{K \alpha}=\right.$ $0.71073 \AA$ ) at $90 \mathrm{~K}$. The program SADABS was used to perform absorption correction. The structure was refined by direct methods using the program SHELXL-97 [18]. Further details on the crystal structure investigation may be obtained from the Fachinformationszentrum Karlsruhe, 76344 EggensteinLeopoldshafen, Germany (Fax: +49 7247808 666; e-mail: crysdata@fiz-karlsruhe.de), on quoting the depository numbers (CSD) presented in Table 2.

X-ray Powder Diffraction. X-ray powder diffraction (PXRD) data were collected on powdered samples using a Bruker D8 Advance X-ray diffractometer utilizing $\mathrm{Cu} \mathrm{K} \alpha$ radiation in the $2 \vartheta$ range of $20^{\circ}-90^{\circ}$ with a step size of $0.02^{\circ}$. Rietveld refinement was performed on the diffraction patterns using the program GSAS[19] to obtain unit cell parameters and weight percentages of any impurity phases present.

Thermoelectric Properties. Thermal diffusivities were measured on polished discs using a Netzsch LFA 457 laser flash system. Thermal conductivity values were obtained from the equation, $k=D \times \rho \times C_{P}$, where $D$ is diffusivity, $\rho$ is density, and $C_{P}$ is heat capacity. Temperature dependent densities were determined using previously measured values of thermal expansion [20] and the samples' densities at room temperature. Heat capacity values were used from previously measured $\mathrm{Yb}_{14} \mathrm{MnSb}_{11}$ [2]. Seebeck 
coefficients were measured by a custom apparatus using the light-pipe method with tungsten-niobium thermocouples under high vacuum [21]. Temperature dependent Hall coefficients and resistivities were measured using the Van der Pauw method with a $0.8 \mathrm{~T}$ magnet with tungsten pressure contact probes at a heating rate of $180 \mathrm{~K} / \mathrm{hr}[22]$.

\section{Results \& Discussion}

Electron microprobe analyses of crystals produced in Sn-flux are shown in Table 1, and revealed that crystals synthesized with low amount of Sc $(p<0.4)$ do not incorporate Sc into their structures, while syntheses with higher amounts $(p>0.6)$ resulted in crystals with 0.3-0.4 Sc. In the case of $Y$, smaller amounts were incorporated in the structure resulting in $x=0.1$ for $p=0.2$, and all compositions with $p=0.4$ or above trending towards $x=0.3-0.4$. Previous work showed maximum substitutions of $x$ $=0.56$ for Sc and $x=0.63$ for $Y[16]$.

Table 1: Atomic \% of Single Crystals Determined by Electron Microprobe Analysis

\begin{tabular}{|c|c|c|c|c|c|c|c|c|}
\hline & \multicolumn{2}{|c|}{ Sample } & \multicolumn{4}{|c|}{ at. $\%$} & & \multirow[t]{2}{*}{ Chemical Formula } \\
\hline & $R E$ & $p^{*}$ & $Y b$ & Sc & $Y$ & $M n$ & $S b$ & \\
\hline Sc0.2F & Sc & 0.2 & $53.9(2)$ & 0 & - & $3.78(1)$ & $42.4(2)$ & $\mathrm{Yb}_{14.01(4)} \mathrm{Mn}_{0.98(3)} \mathrm{Sb}_{11.01(6)}$ \\
\hline Sc0.4F & Sc & 0.4 & $54.1(2)$ & 0 & - & $3.83(5)$ & $42.4(2)$ & $\mathrm{Yb}_{14.04(5)} \mathrm{Mn}_{0.99(1)} \mathrm{Sb}_{11.01(6)}$ \\
\hline Sc0.6F & Sc & 0.6 & $52.5(2)$ & $1.3(2)$ & - & $3.74(5)$ & $42.4(2)$ & $\mathrm{Yb}_{13.65(6)} \mathrm{Sc}_{0.35(4)} \mathrm{Mn}_{0.97(1)} \mathrm{Sb}_{11.00(5)}$ \\
\hline Sc0.8F & Sc & 0.8 & $52.5(2)$ & $1.4(3)$ & - & $3.77(6)$ & $42.3(2)$ & $\mathrm{Yb}_{13.63(4)} \mathrm{Sc}_{0.37(7)} \mathrm{Mn}_{0.98(2)} \mathrm{Sb}_{11.00(4)}$ \\
\hline Y0.2F & $\mathrm{Y}$ & 0.2 & $53.4(2)$ & - & $0.4(3)$ & $3.83(4)$ & $42.4(2)$ & $\mathrm{Yb}_{13.87(5)} \mathrm{Y}_{0.09(7)} \mathrm{Mn}_{0.99(1)} \mathrm{Sb}_{11.01(4)}$ \\
\hline Y0.4F & $\mathrm{Y}$ & 0.4 & $52.8(3)$ & - & $1.2(4)$ & $3.80(3)$ & $42.2(1)$ & $\mathrm{Yb}_{13.71(8)} \mathrm{Y}_{0.3(1)} \mathrm{Mn}_{0.99(1)} \mathrm{Sb}_{10.97(3)}$ \\
\hline Y0.6F & Y & 0.6 & $52.4(1)$ & - & $1.38(4)$ & $3.85(6)$ & $42.3(1)$ & $\mathrm{Yb}_{13.62(4)} \mathrm{Y}_{0.36(1)} \mathrm{Mn}_{1.00(1)} \mathrm{Sb}_{11.00(4)}$ \\
\hline Y0.8F & $\mathrm{Y}$ & 0.8 & $52.9(3)$ & - & $1.24(9)$ & $3.85(6)$ & $42.0(4)$ & $\mathrm{Yb}_{13.73(8)} \mathrm{Y}_{0.32(2)} \mathrm{Mn}_{1.00(1)} \mathrm{Sb}_{10.9(1)}$ \\
\hline
\end{tabular}

${ }_{* p}$ indicates the preparative amount of Sc or $\mathrm{Y}$ added to the flux reaction.

Table 2 shows the results of single crystal X-ray diffraction of $\mathrm{Yb}_{14-x} R E_{x} \mathrm{MnSb}_{11}(\mathrm{RE}=\mathrm{Sc}, \mathrm{Y})$. Each crystal was confirmed to crystallize as the expected $\mathrm{Yb}_{14} \mathrm{MnSb}_{11}$ structure type in the space group $14_{1} /$ acd. Figure 1 shows the structure of $\mathrm{Yb}_{14} \mathrm{MnSb}_{11}$ with the four distinct crystallographic sites for $\mathrm{Yb}$ shown as separate colors. Of these four sites, Sc preferentially substitutes on $\mathrm{Yb}(1)$ and $\mathrm{Yb}(3)$, while $Y$ substitutes on all four. Previous work showed a preference of Ce for the $\mathrm{Yb}(2)$ and $\mathrm{Yb}(4)$ sites [23]. The six-coordinate crystallographic radius of $\mathrm{Sc}^{3+}$ is $0.885 \AA, \mathrm{Y}^{3+}$ is $1.040 \AA$, and $\mathrm{Ce}^{3+}$ is $1.15 \AA$, while $\mathrm{Yb}^{2+}$ is $1.16 \AA$. Hirshfeld surface analysis of chemical bonding indicated $\mathrm{Yb}(2)$ and $\mathrm{Yb}(4)$ to have the largest atomic Hirshfeld surface volumes, while $\mathrm{Yb}(1)$ and $\mathrm{Yb}(3)$ have the smallest [24]. It follows that the $\mathrm{Yb}(1)$ and $\mathrm{Yb}(3)$ sites would be preferred by the smaller $\mathrm{Sc}$ cation, while the $\mathrm{Yb}(2)$ and $\mathrm{Yb}(4)$ sites would be preferred by the larger Ce cation. The $Y$ cation appears to be in the right size range to substitute on all four Yb sites. 
Table 2: Results from Single Crystal X-ray Diffraction of $\mathrm{Yb}_{14-x} \mathrm{RE}_{x} \mathrm{MnSb}_{11}(\mathrm{RE}=\mathrm{Sc}, \mathrm{Y})$

\begin{tabular}{|c|c|c|c|c|}
\hline \multirow[b]{2}{*}{ Sample } & \multirow{2}{*}{$\begin{array}{c}\mathrm{Yb}_{14} \mathrm{MnSb}_{11}[25] \\
-\end{array}$} & \multirow{2}{*}{$\begin{array}{c}\text { Sc- } \\
\text { substituted } \\
\text { Sc0.6F }\end{array}$} & \multicolumn{2}{|c|}{ Y-substituted } \\
\hline & & & Y0.2F & Y0.6F \\
\hline$p^{1}$ & 0 & 0.6 & 0.2 & 0.6 \\
\hline$x(\mathrm{XRD})^{2}$ & 0 & 0.37 & 0.13 & 0.53 \\
\hline$T(\mathrm{~K})$ & $90(2)$ & $90(2)$ & $90(2)$ & $90(2)$ \\
\hline$a / \AA$ & $16.586(2)$ & $16.5624(5)$ & $16.591(2)$ & $16.5903(8)$ \\
\hline$c / \AA$ & $21.911(2)$ & $21.9118(7)$ & $21.920(2)$ & $21.942(1)$ \\
\hline$V / \AA^{3}$ & $6027.5(9)$ & $6010.7(3)$ & $6033.6(7)$ & $6039.2(5)$ \\
\hline$c / a$ & 1.3211 & 1.3230 & 1.3212 & 1.3226 \\
\hline$R 1$ & & 0.0259 & 0.0244 & 0.0197 \\
\hline $\begin{array}{l}w R 2 \\
{[I>2 \sigma(I)]}\end{array}$ & & 0.0571 & 0.0538 & 0.0413 \\
\hline GooF & & 1.097 & 1.355 & 1.425 \\
\hline $\begin{array}{l}\text { Largest diff } \\
\text { peak and } \\
\text { hole }\left(e \AA^{-3}\right)\end{array}$ & & $\begin{array}{l}1.526 \\
\text { and } \\
-1.426\end{array}$ & $\begin{array}{c}1.433 \\
\text { and } \\
-1.168\end{array}$ & $\begin{array}{c}1.290 \\
\text { and } \\
-1.235\end{array}$ \\
\hline Occ. sites & - & $\mathrm{Yb} 1+\mathrm{Yb} 3$ & $\begin{array}{c}\mathrm{Yb} 1+\mathrm{Yb} 2 \\
+\mathrm{Yb} 4\end{array}$ & $\mathrm{Yb} 1+\mathrm{Yb} 2+\mathrm{Yb} 3+\mathrm{Yb} 4$ \\
\hline $\begin{array}{l}\text { CSD- } \\
\text { number }\end{array}$ & & 430761 & 430762 & 430763 \\
\hline
\end{tabular}

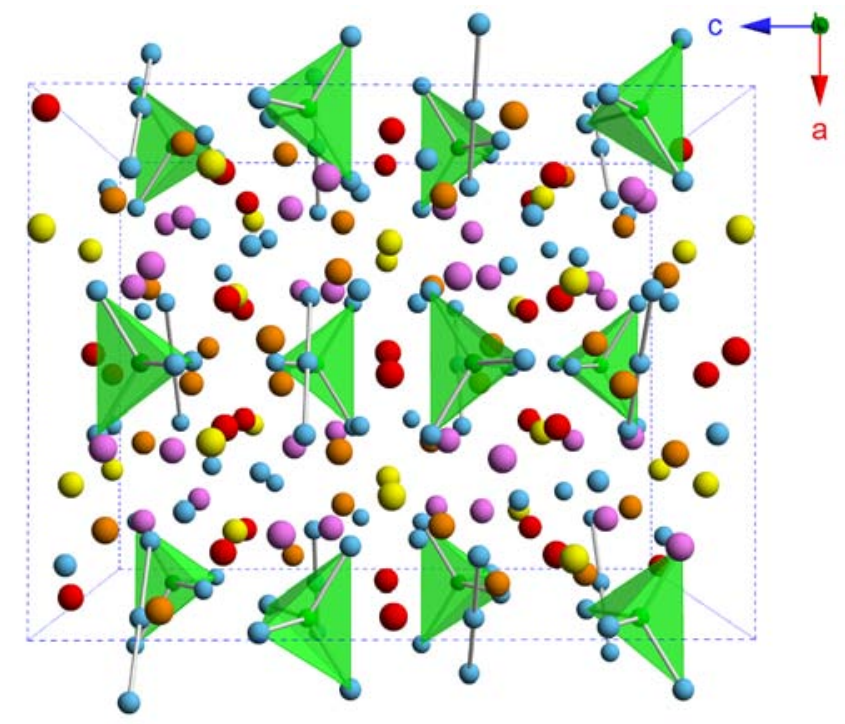

Figure 1: Structure of $\mathrm{Yb}_{14} \mathrm{MnSb}_{11}$ with $\mathrm{Mn}$ atoms indicated in green, $\mathrm{Sb}$ in blue, $\mathrm{Yb}(1)$ in orange, $\mathrm{Yb}(2)$ in red, $\mathrm{Yb}(3)$ in yellow, and $\mathrm{Yb}(4)$ in pink.

Figure 2 compares the unit cell volumes for $\mathrm{Yb}_{14-x} \mathrm{RE}_{x} \mathrm{MnSb}_{11}$ ( $\mathrm{RE}=\mathrm{Sc}, \mathrm{Y}$, Ce [23]). As seen with other rare earth elements such as $\mathrm{Ce}, \operatorname{Pr}, \mathrm{Sm}$, and $\mathrm{Tm},[9,23,25]$ Y substitution leads to an increase in unit cell volume, though not as much as with the larger Ce. This unit cell expansion is accompanied by 
overall increases in bond lengths (see Supporting Information for selected bond lengths and angles), and a slight reduction in the Jahn-Teller distortion of the $\mathrm{MnSb}_{4}{ }^{9-}$ tetrahedron. In the case of Sc, substitution for $\mathrm{Yb}$ leads to a decrease in unit cell volume, reaching a minimum of $6006.6(8) \AA^{3}$ for $x=0.37(7)$. While the majority of the bond lengths in the Sc-substituted crystal decrease, a few of them increase, most notably the $\mathrm{Sb}(2)-\mathrm{Mn}$ distance. In addition to this length increase, the $\mathrm{MnSb}_{4}{ }^{9-}$ tetrahedron also undergo a reduction in distortion. This suggests that the increase in cell size observed in other $3+$ substituted $\mathrm{Yb}_{14} \mathrm{MnSb}_{11}$ compounds is due to the additional electron introduced, which in the case of Sc substitution is not enough to counteract the small size of the cation. As seen in $\mathrm{Yb}_{14} \mathrm{Mn}_{1-\mathrm{x}} \mathrm{Al}_{\mathrm{x}} \mathrm{Sb}_{11}$, the decrease in the distortion of the tetrahedron causes an elongation of the $c$ axis [12].

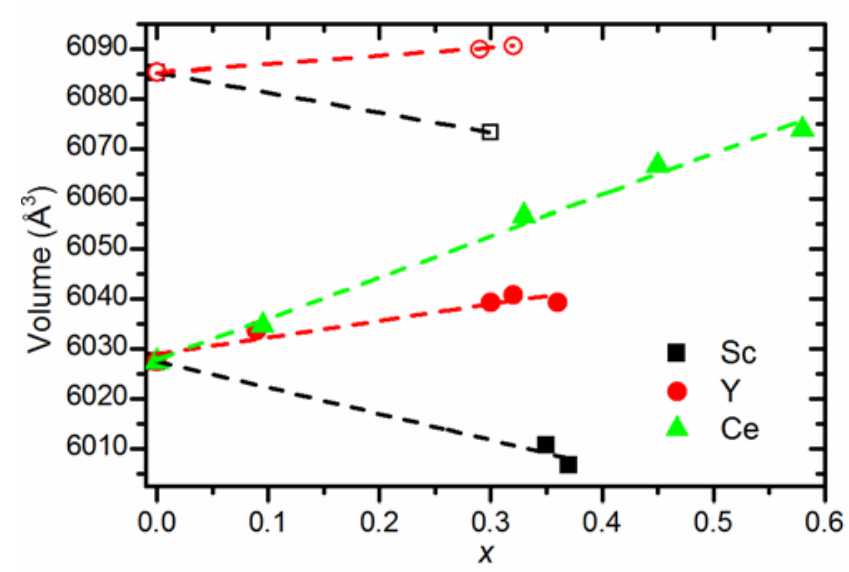

Figure 2: Unit cell volume of $\mathrm{Yb}_{14-x} \mathrm{RE}_{x} \mathrm{MnSb}_{11}(\mathrm{RE}=\mathrm{Sc}, \mathrm{Y}, \mathrm{Ce}$ ) from single crystal $\mathrm{XRD}$ (filled markers) at $90 \mathrm{~K}$ and powder XRD of samples made using powder metallurgy (empty markers) at room temperature vs the rare earth content $x$ as determined by electron microprobe. The cell volumes for Ce substituted $\mathrm{Yb}_{14} \mathrm{MnSb}_{11}$ are from a previous single crystal study [23].

Figure 3 shows electron microprobe backscatter images and X-ray maps for three samples of $\mathrm{Yb}_{14-\mathrm{x}} \mathrm{RE}_{\mathrm{x}} \mathrm{MnSb}_{11}$ with $\mathrm{x} \sim 0.3$ made via ball milling, annealing and spark plasma sintering (SPS): Sc0.4, Y0.4-A, and Y0.4-B. The color on the X-ray maps represents the relative amount of each element present, with the relative color scale presented on the right (red = high, black = low totals). The Sc0.4 sample contains a uniform background of small regions containing slightly larger amounts of Sc while the $\mathrm{Sb}$ content is uniform across the sample. There are a few small regions of $\mathrm{Yb}$ deficiency, but they appear to be associated with regions of excess Sc, consistent with Sc substituting for Yb. The composition of the whole pellet is $\mathrm{Yb}_{14-x} \mathrm{Sc}_{x} \mathrm{MnSb}_{11}$ with small variations in $\mathrm{Sc}$ content. Both $\mathrm{Y}$-substituted samples are more porous than the Sc-substituted, consistent with their lower densities, which were $98 \%$ and $95 \%$ of the theoretical density compared to the fully dense Sc-substituted pellet. However, these images were taken from the edges of the pellets, which appeared to be more porous than the center of the pellets (see Supporting Information). Both of these samples also have larger regions of excess $Y$, and regions that are $\mathrm{Yb}$ deficient. 


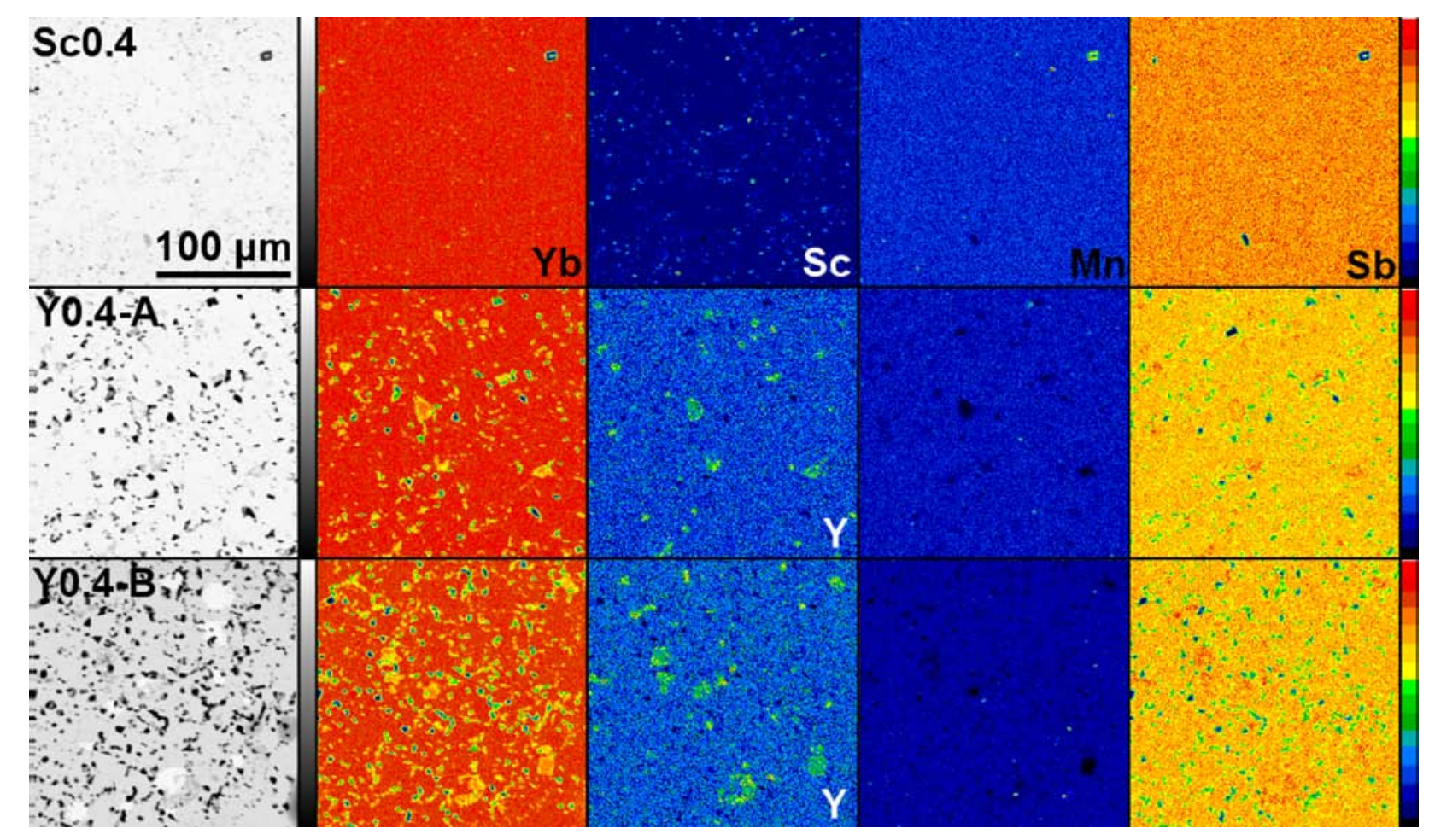

Figure 3: Electron microprobe backscatter images and X-ray maps.

The quantitative data for the electron microprobe of these samples are presented in Table 3. The samples show deficiencies in the amount of $\mathrm{Sb}$, but are close to the expected composition. The amounts of $\mathrm{Sc}$ and $\mathrm{Yb}$ have large standard deviations due to variations in the amount of $R E$ substituting for $\mathrm{Yb}$. However, the main phase of $\mathrm{Yb}_{14-\mathrm{x}} R E_{\mathrm{x}} \mathrm{MnSb}_{11}$ is substituted at $x \sim 0.3$. It is possible that higher temperature annealing or longer times would result in higher concentrations of $R E$ and more homogeneous samples.

Table 3: Quantitative Data from Electron Microprobe Analysis of Samples after Consolidating with SPS

\begin{tabular}{llccccccc}
\hline Sample & \multicolumn{9}{c}{ at. \% } & \multicolumn{2}{c}{ Chemical Formula } \\
\hline & $R E$ & $p^{*}$ & $Y b$ & $S c$ & $Y$ & $M n$ & $S b$ & \\
\hline $\mathrm{Sc0.4}$ & $\mathrm{Sc}$ & 0.4 & $53.3(5)$ & $1.1(5)$ & - & $3.77(7)$ & $41.8(3)$ & $\mathrm{Yb}_{13.8(1)} \mathrm{Sc}_{0.3(1)} \mathrm{Mn}_{0.98(2)} \mathrm{Sb}_{10.86(8)}$ \\
$\mathrm{YO} 0.4-\mathrm{A}$ & $\mathrm{Y}$ & 0.4 & $53.1(2)$ & - & $1.12(6)$ & $3.83(5)$ & $42.0(3)$ & $\mathrm{Yb}_{13.79(6)} \mathrm{Y}_{0.29(2)} \mathrm{Mn}_{0.99(1)} \mathrm{Sb}_{10.90(7)}$ \\
$\mathrm{Y0.4-B}$ & $\mathrm{Y}$ & 0.4 & $52.7(3)$ & - & $1.25(5)$ & $3.91(3)$ & $42.1(3)$ & $\mathrm{Yb}_{13.70(7)} \mathrm{Y}_{0.32(1)} \mathrm{Mn}_{1.01(1)} \mathrm{Sb}_{10.94(7)}$ \\
\hline
\end{tabular}

*p indicates the preparative amount of Sc or $\mathrm{Y}$.

X-ray powder diffraction patterns and Rietveld refinement plots for Sc0.4, Y0.4-A, and Y0.4-B are available in Supporting Information. Table 4 presents the lattice parameters, unit cell volumes, residuals, and weight percentages of impurity phases from the Rietveld refinements of the X-ray powder diffraction patterns for these three samples. Powder unit cell parameters are also shown in Figure 2, and as seen for the single crystals, there is a reduction in the unit cell size with Sc substitution. A slight expansion of the unit cell is observed with $\mathrm{Y}$ substitution, leading to volumes similar to those seen for comparable compositions of $\mathrm{Pr}$ and $\mathrm{Sm}$ substituted $\mathrm{Yb}_{14} \mathrm{MnSb}_{11}\left(\sim 6090 \AA^{3}\right)$ [9]. Both Y-substituted samples contain small amounts of $\mathrm{Yb}_{2} \mathrm{O}_{3}$ and $\mathrm{Yb}_{4} \mathrm{Sb}_{3}$ impurities. 
Table 4: Room Temperature Rietveld Refinement Results

\begin{tabular}{|c|c|c|c|c|c|c|c|}
\hline Sample & $a(\AA)$ & $c(\AA)$ & $\begin{array}{c}\text { Volume } \\
\left(\AA^{3}\right)\end{array}$ & $\mathbf{R}_{\mathrm{wp}}$ & $\begin{array}{c}\text { \# of } \\
\text { Reflns }\end{array}$ & $\begin{array}{l}\mathrm{Yb}_{2} \mathrm{O}_{3} \\
\text { (\% wt) }\end{array}$ & $\begin{array}{l}\mathrm{Yb}_{4} \mathrm{Sb}_{3} \\
(\% \mathrm{wt})\end{array}$ \\
\hline $\mathrm{Yb}_{14} \mathrm{MnSb}_{11}[2]$ & $16.6264(1)$ & $22.0168(2)$ & $6086.3(1)$ & 0.0335 & 3404 & $1.16(3)$ & \\
\hline Sc0.4 & $16.6110(1)$ & $22.0104(2)$ & $6073.3(1)$ & 0.0365 & 3403 & - & \\
\hline Y0.4-A & $16.6236(1)$ & $22.0369(2)$ & $6089.8(1)$ & 0.0352 & 3403 & $1.22(7) \%$ & $1.10(3) \%$ \\
\hline Y0.4-B & $16.6251(1)$ & $22.0360(2)$ & $6090.6(1)$ & 0.0432 & 3404 & $0.89(5) \%$ & $1.88(6) \%$ \\
\hline
\end{tabular}

Figure 4 shows the carrier concentrations of the sintered pellets compared with those of the previously measured $\mathrm{Yb}_{14} \mathrm{MnSb}_{11}$ prepared in a similar manner, but optimized for the highest $z T$ [2]. While Sc-substituted material has a similar if not slightly lower carrier concentration than $\mathrm{Yb}_{14} \mathrm{MnSb}_{11}$, the lowest carrier concentrations are seen in the Y-substituted samples. The Y-substituted materials show carrier concentrations comparable to the materials substituted by La, Tm, Sm, and Pr, and the Scsubstituted material shows higher carrier concentrations than those rare earth substituted compounds $[6,8,9]$. Since Sc should substitute as a $3+$ cation and $x$ is approximately the same for all samples, these results are surprising, as the Sc-substituted material should show carrier concentrations comparable to materials with similar amounts of a $3+$ cation substituted for $\mathrm{Yb}$. Since the $\mathrm{Sc}^{3+}$ cation substitutes only on $\mathrm{Yb1}$ and $\mathrm{Yb3}$ sites and the size of the unit cell decreases, subtle changes in the chemical bonding may provide differences in the band structure leading to a higher carrier concentration.

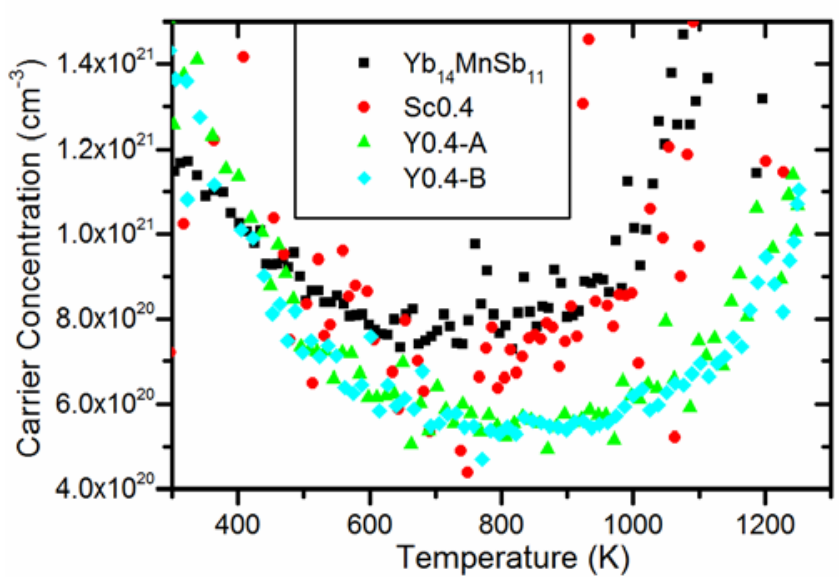

Figure 4: Charge carrier concentration vs temperature for $\mathrm{Yb}_{14-\mathrm{x}} \mathrm{RE} \mathrm{E}_{\mathrm{x}} \mathrm{MnSb}_{11}\left(\mathrm{RE}=\mathrm{Sc}, \mathrm{Y} ; \mathrm{x} \sim 0.3\right.$ ). $\mathrm{Yb}_{14} \mathrm{MnSb}_{11}$ is an optimized sample prepared in a similar manner [2].

Figure 5 shows the electrical resistivity vs temperature of the sintered pellets. At the highest temperatures, the highest resistivities are seen in both of the Y-substituted samples, owing to their lower carrier concentrations. The Sc-substituted sample shows lower resistivity due to its higher carrier concentration, and has a resisitivity that is slightly higher than that of $\mathrm{Yb}_{14} \mathrm{MnSb}_{11}$. The $\mathrm{Y}$-substituted material shows electrical resistivity comparable to the $\mathrm{Tm}$ - and Pr-substituted materials, and lower resistivity than the La- and Sm-substituted materials, while the Sc-substituted material has lower resistivity than all those materials $[6,8,9]$. The lower resistivity is consistent with the higher carrier concentration of the sample. 


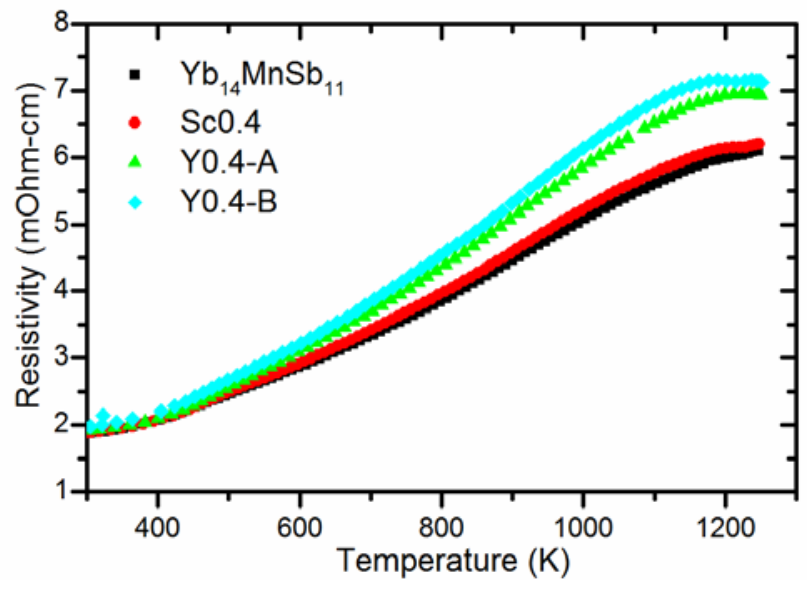

Figure 5: Electrical resistivity vs temperature for $\mathrm{Yb}_{14-\mathrm{x}} \mathrm{RE} \mathrm{x}_{\mathrm{x}} \mathrm{MnSb} b_{11}(\mathrm{RE}=\mathrm{Sc}, \mathrm{Y} ; \mathrm{x} \sim 0.3) . \mathrm{Yb}_{14} \mathrm{MnSb}_{11}$ is an optimized sample prepared in a similar manner [2].

Figure 6 shows the Seebeck coefficients vs temperature of the sintered pellets. The Scsubstituted sample has the highest Seebeck coefficient despite having a larger carrier concentration than the Y-substituted samples. This is likely an effect of the reduced unit cell size in the Sc-substituted sample, as applying pressure increases the Seebeck coefficient [15]. While Y-substituted material shows an increased Seebeck coefficient over $\mathrm{Yb}_{14} \mathrm{MnSb}_{11}$ due to its lower carrier concentration, Sc-substituted material has a similar carrier concentration to $\mathrm{Yb}_{14} \mathrm{MnSb}_{11}$. The only change in the Sc-substituted material that could explain its enhanced Seebeck coefficient is its reduced unit cell volume. At high temperatures the differences between the Seebeck coefficients are small, and these materials are comparable to La-, Tm-, $\mathrm{Pr}$-, and Sm-substituted materials $[6,8,9]$. The effective band gap can be estimated from the peak Seebeck coefficient $\alpha_{\max }$ and the temperature at which it occurs, $T_{\max }$, using Equation 1 [26].

Equation 1

$$
E_{G}=2 \times e \times \alpha_{\max } \times T_{\max }
$$

For a degenerate semiconductor, assuming a single parabolic band model and only acoustic phonon scattering, the effective mass of the charge carriers $m^{*}$ at a temperature $T$ can be estimated with Equation 2:

Equation 2

$$
\alpha=\frac{8 \pi^{2} k_{B}^{2}}{3 e h^{2}} m^{*} T\left(\frac{\pi}{3 n}\right)^{2 / 3}
$$

where $\alpha$ is the Seebeck coefficient and $\mathrm{n}$ is the carrier concentration [27, 28]. The estimated carrier mass $m^{*}$ at $800 \mathrm{~K}$ and band gap $E_{G}$ are listed in Table 5. Sc substitution results in minimal reduction of $E_{G}$ and $m^{*}$, while $Y$ substitution results in a slightly larger reduction in $E_{G}$ and a significant reduction of $m^{*}$. These band gaps are similar to those estimated for Pr-substituted $\mathrm{Yb}_{14} \mathrm{MnSb}_{11}$ [9]. As seen with Lasubstituted $\mathrm{Yb}_{14} \mathrm{MnSb}_{11}$, it appears that 3+ cation substitution leads to a decrease in effective mass [16]. In the case of Sc-substitution that decrease is less significant, which may be attributed to the effect of chemical pressure, since applying pressure on $\mathrm{Yb}_{14} \mathrm{MnSb}_{11}$ causes effective mass to increase [15]. 


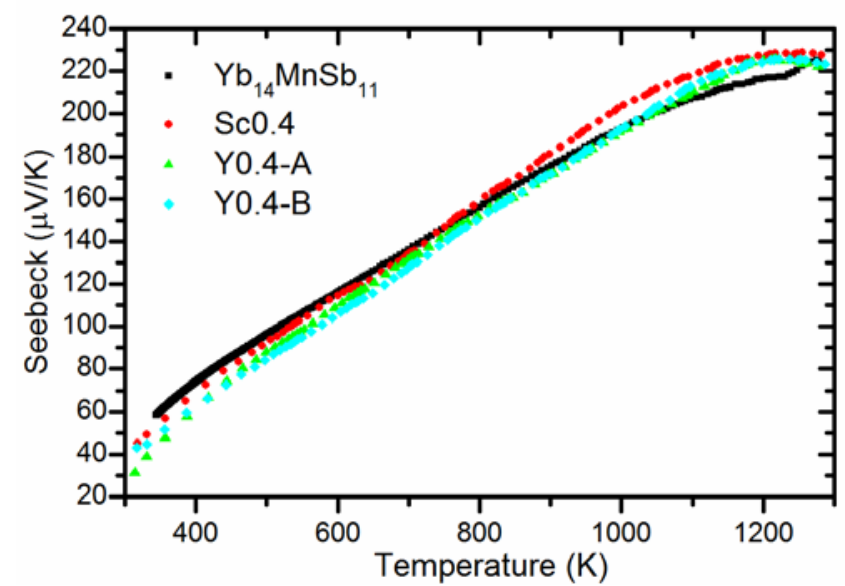

Figure 6: Seebeck coefficients vs temperature for $\mathrm{Yb}_{14-x} R E_{x} M n S b_{11}(R E=S c, Y ; x \sim 0.3) . Y b_{14} M n S b_{11}$ is an optimized sample prepared in a similar manner [2].

Table 5: Estimated Band Gaps and Effective Charge Carrier Mass

\begin{tabular}{lccl}
\hline Sample name & Composition & $E_{G}(\mathrm{eV})$ & $\begin{array}{l}\boldsymbol{m}^{*} / \boldsymbol{m}_{\boldsymbol{e}} \\
\text { at } 800 \mathrm{~K}\end{array}$ \\
\hline $\mathrm{Yb}_{14} \mathrm{MnSb}_{11}[2]$ & - & $\sim 0.58$ & $\sim 11.6$ \\
$\mathrm{Sc0.4}$ & $\mathrm{Yb}_{13.8(1)} \mathrm{Sc}_{0.3(1)} \mathrm{Mn}_{0.98(2)} \mathrm{Sb}_{10.86(8)}$ & $\sim 0.57$ & $\sim 10.9$ \\
$\mathrm{Y0.4-A}$ & $\mathrm{Yb}_{13.79(6)} \mathrm{Y}_{0.29(2)} \mathrm{Mn}_{0.99(1)} \mathrm{Sb}_{10.90(7)}$ & $\sim 0.55$ & $\sim 8.8$ \\
$\mathrm{Y0.4-B}$ & $\mathrm{Yb}_{13.70(7)} \mathrm{Y}_{0.32(1)} \mathrm{Mn}_{1.01(1)} \mathrm{Sb}_{10.94(7)}$ & $\sim 0.55$ & $\sim 8.8$ \\
\hline
\end{tabular}

Figure 7 shows the thermal conductivities of the sintered pellets, with the lattice thermal conductivity obtained by subtracting the electronic component $\kappa_{e}\left(\kappa_{e}=L \sigma T\right.$, where $L$ is the Lorentz number and $\sigma$ is electrical conductivity) from the total thermal conductivity $\mathrm{k}$. The Lorentz number was calculated assuming the single parabolic band model, using the experimental Seebeck coefficients with Equations 3 \& 4:

Equation 3

$$
L=\left(k_{B} / e\right)^{2} \times\left[3 F_{0}(\eta) F_{2}(\eta)-4 F_{1}(\eta)^{2}\right] / F_{0}(\eta)^{2}
$$

Equation 4

$$
\alpha=\left(k_{B} / e\right) \times\left[2 F_{1}(\eta) / F_{0}(\eta)-\eta\right]
$$

where $\eta$ is the reduced Fermi level and $F_{n}(\eta)$ is the Fermi-Dirac integral [29, 30].

The Sc-substituted sample shows the highest thermal conductivity, while the thermal conductivities of the $\mathrm{Y}$-substituted samples are almost identical to that of $\mathrm{Yb}_{14} \mathrm{MnSb}_{11}$. Given that the carrier concentration of the Sc-substituted sample is about the same as $\mathrm{Yb}_{14} \mathrm{MnSb}_{11}$ it is surprising that the thermal conductivity is higher. This may be related to the fact that Sc is significantly lighter than $\mathrm{Y}$ or 
$\mathrm{Yb}$ and contributes to the phonon conduction. It is also possible that the more uniform microstructure of the pellet contributes.

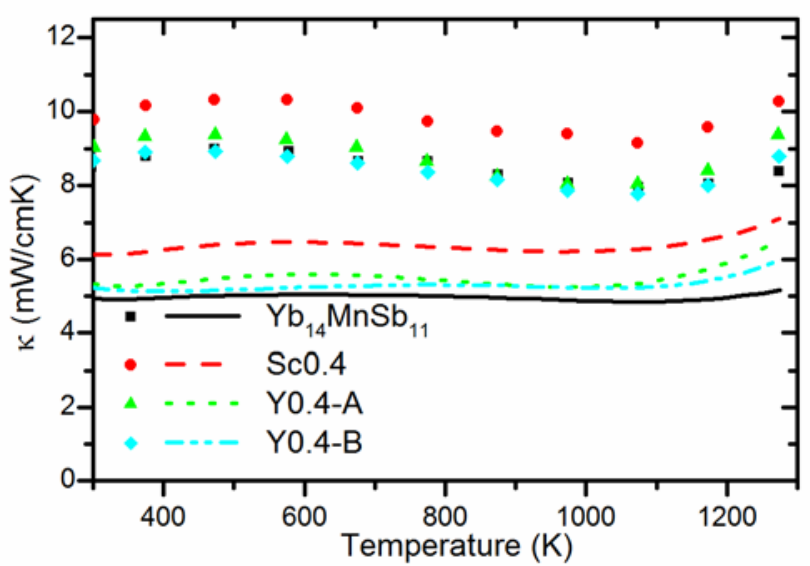

Figure 7: Thermal conductivities vs temperature for $\mathrm{Yb}_{14-x} \mathrm{RE}_{x} \mathrm{MnSb}_{11}(\mathrm{RE}=\mathrm{Sc}, \mathrm{Y} ; \mathrm{x} \sim 0.3)$. Lines represent calculated lattice thermal conductivities. $\mathrm{Yb}_{14} \mathrm{MnSb}_{11}$ is an optimized sample prepared in a similar manner [2].

Figure 8 shows the $z T$ vales of sintered pellets vs temperature compared to $\mathrm{Yb}_{14} \mathrm{MnSb}_{11}$. Both $\mathrm{Sc}$ and $Y$ substitutions result in almost identical $z T$ values, with the Sc-substituted sample slightly exceeding the $z T$ of the Y-substituted sample between 700 and $1100 \mathrm{~K}$. While the Sc-substituted sample has more favorable electronic properties, the lower thermal conductivity of the Y-substituted samples compensates for the differences. None of the samples reach the $z T$ values of the optimized $\mathrm{Yb}_{14} \mathrm{MnSb}_{11}$ [2]. The $z T$ of the materials investigated in this study are comparable to Pr-substituted variants. They are lower than those of the La-substituted compound, and higher than those of Tm- and Sm-substituted materials $[6,8,9]$. It is possible that compensation of the carrier concentration via defects in the structure is responsible and additional efforts preparing stoichiometric phase pure samples may lead to higher $z T$.

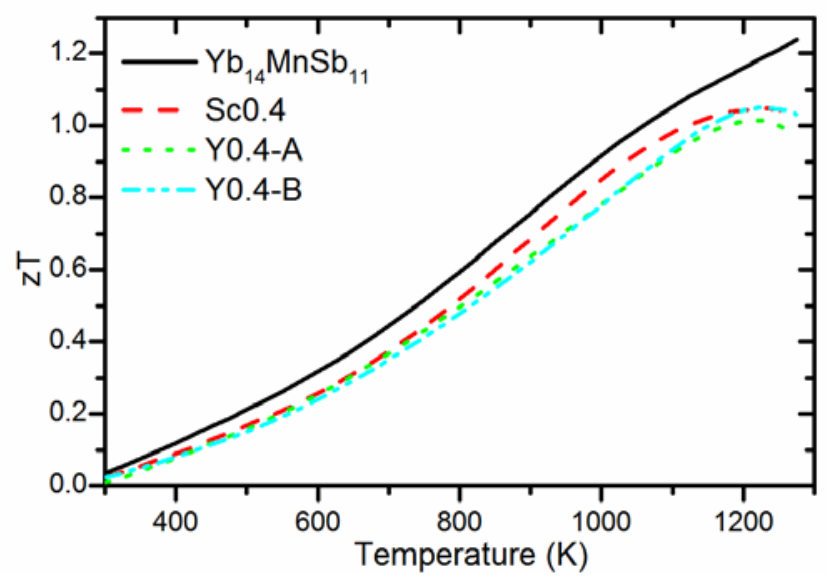

Figure 8: $z T$ values vs temperature for $\mathrm{Yb}_{14-x} \mathrm{RE}_{x} \mathrm{MnSb}_{11}(\mathrm{RE}=\mathrm{Sc}, \mathrm{Y} ; x \sim 0.3) . \mathrm{Yb}_{14} \mathrm{MnSb}_{11}$ is an optimized sample prepared in a similar manner [2]. 


\section{Conclusions}

Substituting $\mathrm{Sc}$ for $\mathrm{Yb}$ in $\mathrm{Yb}_{14} \mathrm{MnSb}_{11}$ reduces the size of the unit cell, with Sc preferentially substituting on the $\mathrm{Yb}(1)$ and $\mathrm{Yb}(3)$ sites. Substituting $\mathrm{Y}$ for $\mathrm{Yb}$ causes a slight increase in the size of the unit cell, and substitutes on all $\mathrm{Yb}$ sites. After $\mathrm{SPS}, \mathrm{Yb}_{14-\mathrm{x}} \mathrm{RE}_{\mathrm{x}} \mathrm{MnSb}_{11} \mathrm{x} \sim 0.3$ samples made by ball milling and annealing have inhomogeneous distributions of Sc and $\mathrm{Y}$. The Y-substituted materials have lower carrier concentrations than the Sc-substituted material, resulting in higher resistivities. Despite a higher carrier concentration, the Sc-substituted material has a slightly higher Seebeck coefficient. Both materials have similar $z T$ values, with a slightly higher thermoelectric figure of merit for the Scsubstituted material between 700 and $1200 \mathrm{~K}$. Neither material achieves the $z T$ values reached by an optimized $\mathrm{Yb}_{14} \mathrm{MnSb}_{11}$ prepared in a similar manner [2]. The improvement of the Seebeck coefficient in the Sc containing sample occurs despite the lower resistivity and higher carrier concentration compared to the $Y$-substituted material. This suggests that the chemical pressure method is a novel approach for improving $z T$ values in $\mathrm{Yb}_{14} \mathrm{MnSb}_{11}$ assuming that the composition can be better controlled in the SPS pellets.

\section{Acknowledgements}

The authors thank Gregory Baxter and Nick Botto for the electron microprobe measurements. Financial support from the DOE Office of Nuclear Energy's Nuclear Energy University Programs and NSF DMR-1405973 is gratefully acknowledged. Part of this research was carried out at the Jet Propulsion Laboratory, California Institute of Technology, under a contract with the National Aeronautics and Space Administration. This work was supported by the NASA Science Mission Directorate's Radioisotope Power Systems. The authors are grateful for fellowships provided by the Rotary Clubs of Darmstadt foundation and the IMI Program of the National Science Foundation under Award No. DMR 08-43934.

\section{References}

[1] S.R. Brown, S.M. Kauzlarich, F. Gascoin, G.J. Snyder, Chem. Mater. 18 (2006) 1873-1877.

[2] J.H. Grebenkemper, Y. Hu, D. Barrett, P. Gogna, C.-K. Huang, S.K. Bux, S.M. Kauzlarich, Chem. Mater. 27 (2015) 5791-5798.

[3] J.Y. Chan, M.M. Olmstead, S.M. Kauzlarich, D.J. Webb, Chem. Mater. 10 (1998) 3583-3588.

[4] G. Cordier, H. Schäfer, M. Stelter, Z. Anorg. Allg. Chem. 519 (1984) 183-188.

[5] C.A. Cox, S.R. Brown, G.J. Snyder, S.M. Kauzlarich, J. Electron. Mater. 39 (2010) 1373-1375.

[6] E.S. Toberer, S.R. Brown, T. Ikeda, S.M. Kauzlarich, G. Jeffrey Snyder, Appl. Phys. Lett. 93 (2008) 062110.

[7] C. Yu, Y. Chen, H. Xie, G.J. Snyder, C. Fu, J. Xu, X. Zhao, T. Zhu, Appl. Phys. Express 5 (2012) 031801.

[8] C.A. Uvarov, M.N. Abdusalyamova, F. Makhmudov, K. Star, J.P. Fleurial, S.M. Kauzlarich, Sci. Adv. Mater. 3 (2011) 652-658.

[9] Y. Hu, S.K. Bux, J.H. Grebenkemper, S.M. Kauzlarich, J. Mater. Chem. C 3 (2015) 10566-10573.

[10] S.R. Brown, E.S. Toberer, T. Ikeda, C.A. Cox, F. Gascoin, S.M. Kauzlarich, G.J. Snyder, Chem. Mater. 20 (2008) 3412-3419.

[11] Y. Hu, J. Wang, A. Kawamura, K. Kovnir, S.M. Kauzlarich, Chem. Mater. 27 (2015) 343-351.

[12] C.A. Cox, E.S. Toberer, A.A. Levchenko, S.R. Brown, G.J. Snyder, A. Navrotsky, S.M. Kauzlarich, Chem. Mater. 21 (2009) 1354-1360.

[13] T. Yi, M.N. Abdusalyamova, F. Makhmudov, S.M. Kauzlarich, J. Mater. Chem. 22 (2012) 1437814384. 
[14] J.R. Sootsman, D.Y. Chung, M.G. Kanatzidis, Angew. Chem. Int. Ed. Engl. 48 (2009) 8616-8639.

[15] A. Akrap, N. Barišić, L. Forró, D. Mandrus, B. Sales, Phys. Rev. B 76 (2007).

[16] B. Sales, P. Khalifah, T. Enck, E. Nagler, R. Sykora, R. Jin, D. Mandrus, Phys. Rev. B 72 (2005) 205207-1-205207-5.

[17] I.R. Fisher, T.A. Wiener, S.L. Bud'ko, P.C. Canfield, J.Y. Chan, S.M. Kauzlarich, Phys. Rev. B 59 (1999) 13829-13834.

[18] G.M. Sheldrick, Acta Crystallogr A 64 (2008) 112-22.

[19] A. C. Larson, A. B. Von Dreele, Los Alamos National Laboratory Report LAUR, 2004.

[20] V. Ravi, S. Firdosy, T. Caillat, E. Brandon, K. Van Der Walde, L. Maricic, A. Sayir, J. Electron. Mater. 38 (2009) 1433-1442.

[21] C. Wood, D. Zoltan, G. Stapfer, Rev. Sci. Instrum. 56 (1985) 719-722.

[22] K.A. Borup, E.S. Toberer, L.D. Zoltan, G. Nakatsukasa, M. Errico, J.P. Fleurial, B.B. Iversen, G.J. Snyder, Rev. Sci. Instrum. 83 (2012) 123902.

[23] J.H. Grebenkemper, S.M. Kauzlarich, APL Mater. 3 (2015) 041503.

[24] S. Kastbjerg, C.A. Uvarov, S.M. Kauzlarich, E. Nishibori, M.A. Spackman, B.B. Iversen, Chem. Mater. 23 (2011) 3723-3730.

[25] J.H. Roudebush, J. Grebenkemper, Y. Hu, N. Kazem, M.N. Abdusalyamova, S.M. Kauzlarich, J. Solid State Chem. 211 (2014) 206-211.

[26] H.J. Goldsmid, J.W. Sharp, J. Electron. Mater. 28 (1999) 869-872.

[27] M. Cutler, J.F. Leavy, R.L. Fitzpatrick, Phys. Rev. 133 (1964) A1143-A1152.

[28] Y. Tang, Z.M. Gibbs, L.A. Agapito, G. Li, H.S. Kim, M.B. Nardelli, S. Curtarolo, G.J. Snyder, Nat Mater 14 (2015) 1223-8.

[29] V.I. Fistul, Heavily Doped Semiconductors. Plenum, New York, 1969.

[30] T. Caillat, J.P. Fleurial, A. Borshchevsky, J. Phys. Chem. Solids 58 (1997) 1119-1125. 